1

\title{
Reverting the mode of action of the mitochondrial $\mathrm{F}_{0} \mathrm{~F}_{1}-\mathrm{ATPase}$ by Legionella pneumophila preserves its replication niche
}

$$
\text { Pedro Escoll }{ }^{1,2, *} \text {, Lucien Platon }{ }^{1,2,3,+, \ddagger} \text {, Mariatou Dramé }{ }^{1,2,4, \ddagger} \text {, Tobias Sahr }{ }^{1,2} \text {, }
$$$$
\text { Silke Schmidt }{ }^{1,2,5} \text {, Christophe Rusniok }{ }^{1,2} \& \text { Carmen Buchrieser }{ }^{1,2, *}
$$

\footnotetext{
${ }^{1}$ Institut Pasteur, Biologie des Bactéries Intracellulaires and, ${ }^{2}$ CNRS UMR 3525, 75024 Paris,
} France, ${ }^{3}$ Faculté des Sciences, Université de Montpellier, 34095 Montpellier, France, ${ }^{4}$ Université de Paris, 75013 Paris, France, ${ }^{5}$ Sorbonne Université, Collège doctoral, 75005 Paris, France

Keywords: Legionella pneumophila, OXPHOS, mitochondria, $\mathrm{F}_{\mathrm{O}} \mathrm{F}_{1}$-ATPase, mitochondrial 6 membrane potential, cell death, macrophages

$9+$ Present address: Institut Pasteur, Génétique du Paludisme et Résistance, Paris, France

$\$$ These authors contributed equally to the work

3 * For correspondence:

$4 \quad$ Pedro Escoll and Carmen Buchrieser

5 Institut Pasteur, Biologie des Bactéries Intracellulaires

628 , rue du Dr. Roux, 75724 Paris Cedex 15, France

Tel: (33-1)-44-38-95-40

8 Fax: (33-1)-45-68-87-86

9 E-mail: pescoll@pasteur.fr and cbuch@pasteur.fr 


\section{ABSTRACT}

32 Legionella pneumophila, the causative agent of Legionnaires' disease, a severe pneumonia, 33 injects via a type-IV-secretion-system (T4SS) more than 300 proteins into macrophages, its main host cell in humans. Certain of these proteins are implicated in reprogramming the metabolism of infected cells by reducing mitochondrial oxidative phosphorylation (OXPHOS) early after infection. Here we show that despite reduced OXPHOS, the mitochondrial membrane potential $\left(\Delta \psi_{\mathrm{m}}\right)$ is maintained during infection of primary human monocyte-derived macrophages (hMDMs). We reveal that L. pneumophila reverses the ATP-synthase activity of the mitochondrial $\mathrm{F}_{\mathrm{O}} \mathrm{F}_{1}$-ATPase to ATP-hydrolase activity in a T4SS-dependent manner, which leads to a conservation of the $\Delta \psi_{\mathrm{m}}$, preserves mitochondrial polarization and prevents macrophage cell death. Analyses of T4SS effectors known to target mitochondrial functions revealed that $L p \mathrm{Spl}$ is partially involved in conserving the $\Delta \psi_{\mathrm{m}}$, but not LncP and MitF. The inhibition of the L. pneumophila-induced "reverse mode" of the $\mathrm{F}_{\mathrm{O}} \mathrm{F}_{1}$-ATPase collapsed the $\Delta \psi_{\mathrm{m}}$ and caused cell death in infected cells. Single-cell analyses suggested that bacterial replication occurs preferentially in hMDMs that conserved the $\Delta \psi_{\mathrm{m}}$ and showed delayed cell death. This direct manipulation of the mode of activity of the $\mathrm{F}_{\mathrm{O}} \mathrm{F}_{1}$-ATPase is a newly identified feature of L. pneumophila allowing to delay host cell death and thereby to preserve the bacterial replication niche during infection. 


\section{INTRODUCTION}

51

Beyond their essential role in cellular bioenergetics, mitochondria are integrated into diverse signaling pathways in eukaryotic cells and perform various signaling functions, such as immune responses or cell death, as they play crucial roles in the regulation of apoptosis (Bock and Tait, 2020). Thus mitochondria are targeted by several intracellular bacteria during infection to modulate their functions to the bacterial advantage (Spier et al., 2019). One of these bacteria is Legionella pneumophila, the causative agent of Legionnaires' disease. We have shown previously that this pathogen targets mitochondrial dynamics during infection of primary human monocyte-derived macrophages (hMDMs) by injecting type IV secretion system (T4SS) effectors such as MitF, leading to a fragmented mitochondrial network via the recruitment of the host fission protein DNM1L to the mitochondrial surface (Escoll et al., 2017b). Importantly, Legionella induced mitochondrial fragmentation at early time points such as 5 hours postinfection (hpi), when bacterial replication has not started yet, and in the absence of cell death signs. The fragmentation of mitochondrial networks provoked a T4SS-dependent reduction of mitochondrial respiration in Legionella-infected macrophages, evidencing a functional connection between mitochondrial dynamics and mitochondrial respiration (Escoll et al., 2017b).

Mitochondrial respiration results from coupling the activity of five complexes in the electron transport chain (ETC) at mitochondrial cristae. In this process, the reduced coenzymes NADH and $\mathrm{FADH}_{2}$ generated at the mitochondrial matrix by the tricarboxilic acid (TCA) cycle are oxidized at Complexes I and II where their electrons are extracted to energize the mitochondrial ETC (Nolfi-Donegan et al., 2020). The sequential transit of these electrons through Complexes I, III and IV allows to pump protons from the matrix to the intermembrane space (IMS) and at Complex IV, diatomic oxygen $\mathrm{O}_{2}$ serves as the terminal electron acceptor and $\mathrm{H}_{2} \mathrm{O}$ is formed. The increased concentration of protons $\left[\mathrm{H}^{+}\right]$at the IMS, compared to $\left[\mathrm{H}^{+}\right]$at the matrix, generates the mitochondrial membrane potential $\left(\Delta \psi_{\mathrm{m}}\right)$. This is necessary reveito produce ATP by fueling the rotation of Complex $\mathrm{V}$, the mitochondrial $\mathrm{F}_{\mathrm{O}} \mathrm{F}_{1}$-ATPase, in a process termed oxidative phosphorylation, OXPHOS (Nolfi-Donegan et al., 2020). Our previous studies determined that at 5 hpi L. pneumophila, by altering mitochondrial dynamics, reduced OXPHOS as well as the cellular ATP content in hMDMs in a T4SS-depended manner (Escoll et al., 2017b).

Why L. pneumophila and other species of intracellular bacteria reduce mitochondrial OXPHOS during infection of host cells remains a matter of debate (Escoll and Buchrieser, 
2018; Russell et al., 2019). As intracellular bacteria can obtain resources only from host cells, it has been suggested that halting mitochondrial OXPHOS during infection might benefit pathogenic bacteria by redirecting cellular resources, such as glycolytic or TCA intermediates, to biosynthetic pathways that might sustain intracellular bacterial replication instead of fueling mitochondria (Escoll and Buchrieser, 2018; Russell et al., 2019). For instance, it has been shown that Mycobacterium tuberculosis redirects pyruvate to fatty acid synthesis and Chlamydia trachomatis subverts the pentose phosphate pathway to increase the synthesis of nucleotides for its own intracellular growth (Siegl et al., 2014; Singh et al., 2012). On the other hand, upon sensing bacterial lipopolysaccharides, macrophages redirect mitochondrial TCA intermediates, such as citrate or succinate, to drive specific immune functions such as the production of cytokines or the generation of antimicrobial molecules (Escoll and Buchrieser, 2019; Russell et al., 2019; O’Neill and Pearce, 2016). Thus, while these metabolic shifts, which are redirecting resources from mitochondria to the cytoplasm should be activated in macrophages to develop their antimicrobial functions, they could also benefit intracellular bacteria, as more resources would be available in the cytoplasm for bacterial growth. Importantly, reduction of OXPHOS may lead to decreased $\Delta \psi_{\mathrm{m}}$ and ATP production at mitochondria, which are events that trigger the activation of cell death programs. How intracellular bacteria withdraw OXPHOS, deal with the subsequent $\Delta \psi_{\mathrm{m}}$ drop and host cell death but manage to preserve their host cell to conserve their replication niche is a question that remains poorly understood.

To answer this question, we monitored the evolution of mitochondrial polarization during infection of hMDMs by L. pneumophila, and showed that in the absence of OXPHOS, L. pneumophila regulates the enzymatic activity of the mitochondrial $\mathrm{F}_{\mathrm{O}} \mathrm{F}_{1}$-ATPase during infection. This allows maintaining the $\Delta \psi_{\mathrm{m}}$ and delays cell death of infected hMDMs in a T4SSdependent manner. Our results identified a new virulence mechanism of L. pneumophila, namely the manipulation of the mitochondrial $\mathrm{F}_{\mathrm{O}} \mathrm{F}_{1}-\mathrm{ATPase}$ to preserve the integrity of infected host cells and thereby the maintenance of the bacterial replication niches.

\section{RESULTS}

Despite L. pneumophila-induced Reduction of Mitochondrial Respiration, the

\section{Mitochondrial Membrane Potential Is Maintained}

We have previously shown that L. pneumophila strain Philadelphia JR32 impairs mitochondrial respiration during infection (Escoll et al., 2017b). Here we analyzed L. pneumophila strain Paris (Lpp) to learn whether this is a general characteristic of L. pneumophila infection. We infected 
hMDMs with Lpp WT or a T4SS-deficient mutant ( $\triangle$ dotA) for 6 hours and analyzed their

117 mitochondrial function compared to uninfected hMDMs by using a cellular respiratory control

118 assay in living cells (Brand and Nicholls, 2011; Connolly et al., 2018). This assay determines

119 oxygen consumption rate (OCR) in basal conditions and during the sequential addition of

120 mitochondrial respiratory inhibitors. OCR variations observed indicate how mitochondrial

121 respiration is functioning in a cell population (Figure 1A and S1A). Our results showed that

122 basal respiration is significantly reduced $(\mathrm{p}<0.0001)$ in WT-infected hMDMs compared to

$123 \Delta d o t A$ - and non-infected hMDMs (Figure 1A and 1B). This indicates that $\mathrm{O}_{2}$ consumption,

124 which is predominantly driven by ATP turnover and the flow of $\mathrm{H}^{+}$to the matrix through the

125 mitochondrial $\mathrm{F}_{\mathrm{O}} \mathrm{F}_{1}$-ATPase, is severely impaired in WT-infected hMDMs. Further analysis of

126 OCR changes upon addition of oligomycin, an inhibitor of the mitochondrial $\mathrm{F}_{\mathrm{O}} \mathrm{F}_{1}$-ATPase,

127 indicated that the rate of mitochondrial respiration coupled to ATP synthesis is highly reduced

128 in WT-infected hMDMs, compared to $\Delta d o t A$ - or non-infected cells. Other respiratory

129 parameters such as proton leak were also reduced in WT-infected macrophages (Figure 1A,

130 S1A and S1B). Subsequent addition of an uncoupler to create a $\mathrm{H}^{+}$short-circuit across the inner

131 mitochondrial membrane (IMM), such as FCCP, allowed measuring the maximum respiration

132 rate and the spare respiratory capacity, revealing that both were severely impaired in WT-

133 infected cells compared to $\Delta$ dotA- and non-infected hMDMs (Figure 1A, S1A and S1B).

134 Finally, inhibition of the respiratory complexes I and III with rotenone and antimycin A,

135 respectively, measured $\mathrm{O}_{2}$ consumption driven by non-mitochondrial processes, such as

136 cytoplasmic $\mathrm{NAD}(\mathrm{P}) \mathrm{H}$ oxidases, which showed similar levels of non-mitochondrial $\mathrm{O}_{2}$

137 consumption in all infection conditions (Figure 1A, S1A and S1B).

138 Taken together, our results indicated that several mitochondrial respiration parameters were severely altered during infection with Lpp-WT, including respiration coupled to ATP

140 production. Importantly, some of the respiratory parameters measured that are oligomycin-

141 sensitive were reduced in Lpp-WT-infected hMDMs but not in $\Delta$ dot $A$-infected cells, suggesting

142 that the mitochondrial $\mathrm{F}_{\mathrm{O}} \mathrm{F}_{1}-\mathrm{ATPase}$ activity may be altered during L. pneumophila infection in

143 a T4SS-depended manner.

144 The transition of electrons across mitochondrial ETC complexes allows the extrusion of $\mathrm{H}^{+}$ 145 from the matrix to the IMS generating a $\mathrm{H}^{+}$circuit where the mitochondrial $\mathrm{F}_{\mathrm{O}} \mathrm{F}_{1}$-ATPase is the 146 dominant $\mathrm{H}^{+}$re-entry site during active ATP synthesis by OXPHOS. In cellular steady-state 147 conditions, extrusion and re-entry $\mathrm{H}^{+}$fluxes across mitochondrial membranes are balanced 148 (Brand and Nicholls, 2011). Therefore, any exogenous alteration of ATP turnover and/or $\mathrm{F}_{0} \mathrm{~F}_{1-}$ 
149 ATPase activity influences this $\mathrm{H}^{+}$circuit and might be reflected in $\Delta \psi_{\mathrm{m}}$ levels. Thus, we 150 decided to quantify the $\Delta \psi_{\mathrm{m}}$ in infected cells. We developed a miniaturized high-content assay

151 based on kinetic measurements of TMRM fluorescence in non-quenching conditions (10nM), 152 where TMRM fluorescence in mitochondria is proportional to the $\Delta \psi_{\mathrm{m}}$ (Connolly et al., 2018; 153 Duchen et al., 2003). This assay allowed to measure changes in the $\Delta \psi_{\mathrm{m}}$ at the single-cell level 154 and in thousands of living cells during the course of infection (Figure 1C). Image analysis 155 showed that the $\Delta \psi_{\mathrm{m}}$ slightly increased in Lpp-WT-, Lpp- $\Delta$ dotA- and non-infected cell 156 populations during the first hours of infection (1-3 hpi), and progressively decreased during the 157 time-course with no differences between the infection conditions (Figure 1D). Single-cell 158 analyses (Figure 1E and S1C) showed that Lpp-WT-, Lpp- $\Delta d o t A$ - and non-infected single $159 \mathrm{hMDMs}$ showed a wide range of $\Delta \psi_{\mathrm{m}}$ values at any time-point (Figure S1C) with no significant 160 differences between them at 6 hpi (Figure 1E). Thus, despite a significant reduction of 161 OXPHOS the $\Delta \psi_{\mathrm{m}}$ was maintained in infected cells, suggesting that L. pneumophila manipulates the mitochondrial ETC to conserve the $\Delta \psi_{\mathrm{m}}$ of hMDMs in the absence of OXPHOS.

\section{L. pneumophila Infection Induces the "Reverse Mode" of the Mitochondrial FoF F $_{1}$ ATPase} in a T4SS-depended Manner

166 The mitochondrial $\mathrm{F}_{\mathrm{O}} \mathrm{F}_{1}-\mathrm{ATPase}$ is a fascinating molecular machine that rotates clockwise when it works in the "forward mode", synthesizing ATP by using the $\Delta \psi_{\mathrm{m}}$ generated by the $\mathrm{H}^{+}$ circuit (Figure 2A, left). It can also rotate counter-clockwise when it works in the "reverse mode". In this case, it hydrolyzes ATP to maintain $\Delta \psi_{\mathrm{m}}$ in the absence of OXPHOS (Figure 2A, right). As our results showed that L. pneumophila highly reduced OXPHOS, likely by an alteration of the $\mathrm{F}_{\mathrm{O}} \mathrm{F}_{1}$-ATPase activity, while the $\Delta \psi_{\mathrm{m}}$ was conserved, we investigated in which activity mode the $\mathrm{F}_{\mathrm{O}} \mathrm{F}_{1}$-ATPase worked during Legionella infection. A widely used method to investigate the directionality of the $\mathrm{F}_{\mathrm{O}} \mathrm{F}_{1}$-ATPase in intact cells is to monitor changes in $\Delta \psi_{\mathrm{m}}$ after the addition of $\mathrm{F}_{\mathrm{O}} \mathrm{F}_{1}$-ATPase inhibitors, such as oligomycin or DCCD (Connolly et al., 2018; Gandhi et al., 2009). These inhibitors block both modes of function, thus if the $\mathrm{F}_{\mathrm{O}} \mathrm{F}_{1^{-}}$ ATPase is working in the "forward mode" the $\Delta \psi_{\mathrm{m}}$ will increase after adding the inhibitor, as the inhibition of the $\mathrm{H}^{+}$flux to the matrix through the ATPase leads to an accumulation of $\mathrm{H}^{+}$ at the IMS (Figure 2B, left). If $\Delta \psi_{\mathrm{m}}$ decreases after ATPase inhibition, the $\mathrm{F}_{\mathrm{O}} \mathrm{F}_{1}$-ATPase works in the "reverse mode", since now $\mathrm{H}^{+}$cannot translocate to the IMS to maintain the $\Delta \psi_{\mathrm{m}}$ (Figure

$1802 \mathrm{~B}$, right). Here, we used the aforementioned TMRM high-content assay to monitor the $\Delta \psi_{\mathrm{m}}$ in

181 living hMDMs at $6 \mathrm{hpi}$, when OXPHOS is impaired and $\Delta \psi_{\mathrm{m}}$ is maintained. 
First, we recorded a baseline and then added medium as a control. As expected, this did not alter $\Delta \psi_{\mathrm{m}}$ in any infection condition (Figure 2C and 2D). However, the addition of FCCP completely depolarized mitochondria, leading to an abrupt drop of $\Delta \psi_{\mathrm{m}}$ in Lpp-WT-, Lpp$\triangle d o t A$ - and non-infected hMDMs (Figure $2 \mathrm{C}$ and $2 \mathrm{E}$ ), demonstrating that this assay can monitor changes in the $\Delta \psi_{\mathrm{m}}$ simultaneously in hundreds of infected cells. To analyze whether the $\mathrm{F}_{\mathrm{O}} \mathrm{F}_{1}$-ATPase worked in the synthase (forward) or the hydrolase (reverse) mode we added oligomycin (Figure 2F) or DCCD (Figure 2G) to the infected cells. The $\Delta \psi_{\mathrm{m}}$ increased in noninfected or $\triangle d$ dotA-infected hMDMs, which suggested that the ATPase worked in the "forward mode" in these infection conditions. In contrast, the addition of oligomycin to Lpp-WT-infected hMDMs had no effect on the $\Delta \psi_{\mathrm{m}}$ (Figure 2F), while addition of DCCD decreased the $\Delta \psi_{\mathrm{m}}$ (Figure 2G). Thus, our results indicate that the $\mathrm{F}_{\mathrm{O}} \mathrm{F}_{1}$-ATPase worked in the "forward mode" in non-infected or $\Delta$ dot $A$-infected macrophages, whereas the $\mathrm{F}_{\mathrm{O}} \mathrm{F}_{1}$-ATPase worked in the "reverse mode" during infection of hMDMs with the WT strain. This suggests that the induction of the "reverse mode" depends on the action of T4SS effector(s).

\section{The T4SS Effector LpSPL Participates in the Induction of the "Reverse Mode" of the} Mitochondrial FoF 1 -ATPase During Infection

Among the more than 300 bacterial effectors that L. pneumophila injects into host cells through its T4SS (Mondino et al., 2020), three have been shown to target mitochondrial structures or functions. LncP is a T4SS effector targeted to mitochondria that assembles in the inner mitochondrial membrane (IMM) and seems to transport ATP across mitochondrial membranes (Dolezal et al., 2012). The effector $\mathrm{LpSpl}$ (also known as LegS2) was suggested to target mitochondria (Degtyar et al., 2009), the endoplasmic reticulum (ER, (Rolando et al., 2016), and mitochondrial-associated membranes, MAMs ((Escoll et al., 2017a). LpSpl encodes a sphingosine-1 phosphate (S1P) lyase that directly targets the host sphingolipid metabolism and restrains autophagy in infected cells. MitF (LegG1) activates the host small GTPase Ran to promote mitochondrial fragmentation during infection of human macrophages (Escoll et al., 2017b).

To learn if any of these effectors is involved in the T4SS-dependent induction of the "reverse mode" of the $\mathrm{F}_{\mathrm{O}} \mathrm{F}_{1}$-ATPase, we infected hMDMs during 6 hours with Lpp-WT or its isogenic mutants lacking the T4SS (Lpp- $\Delta \operatorname{dot} A)$, lacking the effector LncP (Lpp- $\Delta \operatorname{lnc} P$ ), lacking the effector LpSpl (Lpp- $\Delta s p l$ ), and L. pneumophila strain Philadelphia JR32 (JR32-WT) and its isogenic mutants lacking the T4SS (JR32- $\Delta i c m T)$ or the effector MitF (JR32- $\Delta m i t F)$. Using the TMRM high-content assay, we measured the $\Delta \psi_{\mathrm{m}}$ after the inhibition of the $\mathrm{F}_{\mathrm{O}} \mathrm{F}_{1}$-ATPase by 


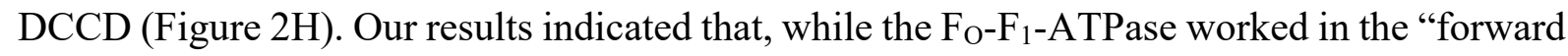
mode" in non-infected hMDMs and during infection with T4SS-deficient mutants (Lpp- $\triangle$ dotA and JR32- $\Delta i c m T$ ), the $\mathrm{F}_{\mathrm{O}} \mathrm{F}_{1}$-ATPase worked in the "reverse mode" during infection with the Lpp-WT and JR32-WT strains (Figure 2G). Infection with Lpp- $\Delta \operatorname{lncP}$ and JR32- $\Delta m i t F$ were not significantly different compared to the WT strains, suggesting that these effectors are not involved in the induction of the "reverse mode" of the mitochondrial ATPase. However, mitochondria of cells infected with Lpp- $\Delta s p l$ showed a significantly higher $\Delta \psi_{\mathrm{m}}$ after DCCD treatment than mitochondria of cells infected with Lpp-WT $(\mathrm{p}=0.0006)$, and a significantly lower $\Delta \psi_{\mathrm{m}}$ after DCCD treatment than mitochondria of cells infected with the Lpp- $\Delta d o t A$ strain ( $\mathrm{p}=0.0034)$. This suggests that $L p \mathrm{Spl}$ is partially involved in the induction of the "reverse mode" of the $\mathrm{F}_{\mathrm{O}} \mathrm{F}_{1}$-ATPase, however other additional T4SS effector(s) seem to participate in the modulation of the $\mathrm{F}_{\mathrm{O}} \mathrm{F}_{1}$-ATPase activity mode.

\section{Death of Infected Macrophages}

To further analyze the importance of the activity mode of the $\mathrm{F}_{\mathrm{O}} \mathrm{F}_{1}$-ATPase during infection, we used BTB06584 (hereafter called BTB), a specific inhibitor of the "reverse mode" of the mitochondrial $\mathrm{F}_{\mathrm{O}} \mathrm{F}_{1}$-ATPase (Ivanes et al., 2014). We used the TMRM high-content assay and added BTB to non-infected, Lpp-WT- or Lpp- $\Delta$ dotA-infected hMDMs at 6 hpi. As shown in Figure $3 \mathrm{~A}$, the $\Delta \psi_{\mathrm{m}}$ collapsed specifically and significantly in WT infected cells (Figure 3B and 3C) compared to non-infected $(\mathrm{p}=0.0022)$ and $\Delta d o t A$-infected cells $(\mathrm{p}=0.0238)$, further confirming that the $\mathrm{F}_{\mathrm{O}} \mathrm{F}_{1}$-ATPase works in the "reverse mode" during WT infection. Indeed, the addition of BTB to Lpp-WT-infected hMDMs led to a significant reduction of the $\Delta \psi_{\mathrm{m}}$ $(\mathrm{p}<0.0001)$ at every time point post-infection $(1-10 \mathrm{hpi})$ and at the single-cell level compared to non-treated Lpp-WT-infected cells (Figure 3D), further confirming that conservation of $\Delta \psi_{\mathrm{m}}$ during L. pneumophila infection is caused by induction of $\mathrm{F}_{\mathrm{O}}-\mathrm{F}_{1}-\mathrm{ATPase}$ "reverse mode".

As OXPHOS cessation and $\Delta \psi_{\mathrm{m}}$ collapse can trigger cell death, we reasoned that induction of the "reverse mode" of mitochondrial ATPase by L. pneumophila to maintain $\Delta \psi_{\mathrm{m}}$ in the absence of OXPHOS might delay cell death of infected cells. To test this hypothesis, we infected hMDMs with Lpp-WT and treated them with BTB or left them untreated, and then measured the percentage of living cells among infected cells (Figure 4A). Our results showed that the percentage of living, infected cells significantly decreased after 10 hpi in BTB-treated infected hMDMs compared to non-treated cells. As this reduction in the percentage of living, infected cells upon "reverse mode" inhibition might be caused by increased cell death, we used 
our high-content assay to measure Annexin- $\mathrm{V}$, a marker of early apoptosis, in a high number of living hMDMs during infection (Figure 4B and 4C). While addition of BTB during 24 hours did not increase the percentage of Annexin- $\mathrm{V}^{+}$cells in non-infected cells, the addition of this "reverse mode" inhibitor to Lpp-WT-infected hMDMs significantly increased the percentage of Annexin- $\mathrm{V}^{+}$cells compared to non-treated cells $(\mathrm{p}=0.0312)$. This suggests that the inhibition of the "reverse mode" by BTB leads to a reduction in the percentage of infected cells as increased cell death occurs specifically in infected cells. Single-cell analysis at 12 and $18 \mathrm{hpi}$ (Figure 4D and S2A) also showed higher levels of Annexin-V intensity in BTB-treated LppWT-infected hMDMs compared to non-treated infected cells $(\mathrm{p}<0.0001)$. BTB-treated infected cells also showed higher Hoechst nuclear levels compared to non-treated infected cells, a sign of nuclear condensation typical of apoptotic cells (Figure S2B), which further indicates that inhibition of the Legionella-induced ATPase "reverse mode" ignites cell death of infected macrophages. Taken together, our results suggest that the Legionella-induced "reverse mode" of the mitochondrial $\mathrm{F}_{\mathrm{O}} \mathrm{F}_{1}-\mathrm{ATPase}$ aids to conserve $\Delta \psi_{\mathrm{m}}$ during infection to delay cell death of infected macrophages.

To simultaneously monitor $\Delta \psi_{\mathrm{m}}$ and early cell death signs in the same infected cell, we multiplexed Annexin-V and TMRM signals in our living cell assay (Figure 4E, S2C and S2D). L. pneumophila-infected macrophages where the "reverse mode" activity of the $\mathrm{F}_{\mathrm{O}} \mathrm{F}_{1}$-ATPase was inhibited by BTB suffered a collapsed $\Delta \psi_{\mathrm{m}}$ and showed higher levels of Annexin-V at 12 and 18 hpi (Figure 4E and S2D) compared to non-treated cells. Thus both events, collapse of the $\Delta \psi_{\mathrm{m}}$ and triggered cell death, occurred in the same infected cell when the Legionellainduced "reverse mode" activity of the $\mathrm{F}_{\mathrm{O}} \mathrm{F}_{1}$-ATPase was inhibited. Furthermore, when the size of the bacterial vacuole was correlated with the $\Delta \psi_{\mathrm{m}}$ and cell death at the single-cell level (12 and 18 hpi, Figure $4 \mathrm{~F}$ and $4 \mathrm{G}$ respectively), intracellular bacterial replication occurred preferentially in those infected macrophages with intermediate levels of TMRM (non-collapsed $\Delta \psi_{\mathrm{m}}$ ) and low Annexin-V levels (yellow color scale, Figure 4F and 4G), further indicating that conservation of $\Delta \psi_{\mathrm{m}}$ and delayed cell death are needed to guarantee the survival of infected macrophages to ensure bacterial replication.

277 We show here that by inducing the "reverse mode" of the mitochondrial $\mathrm{F}_{\mathrm{O}} \mathrm{F}_{1}$-ATPase,

278 L. pneumophila circumvents the collapse of $\Delta \psi_{\mathrm{m}}$ and cell death caused by OXPHOS cessation 279 in infected cells. This mechanism, which partially involves the T4SS effector $L p$ Spl, maintains the $\Delta \psi_{\mathrm{m}}$ and delays host cell death during infection, thus preserving bacterial replication niches 
281 in conditions where mitochondrial respiration is abruptly reduced. Indeed, not only

282 L. pneumophila, but also several other intracellular bacterial pathogens, such as

283 Mycobacterium tuberculosis or Chlamydia pneumoniae, reduce mitochondrial OXPHOS

284 during infection (Siegl et al., 2014; Singh et al., 2012)(Escoll and Buchrieser, 2019). OXPHOS

285 reduction allows the pathogen to redirect cellular resources from mitochondria to the cytoplasm,

286 which enhances glycolysis and biosynthetic pathways that can provide intracellular bacteria

287 with resources needed for bacterial growth (Escoll and Buchrieser, 2018; Russell et al., 2019).

288 In contrast, OXPHOS cessation in macrophages also enhances the biosynthetic pathways

289 leading to the synthesis of cytokines and antimicrobial compounds (O'Neill and Pearce, 2016;

290 Russell et al., 2019). Furthermore, OXPHOS reduction may trigger profound consequences for

291 host cells, such as the collapse of $\Delta \psi_{\mathrm{m}}$ that may lead to subsequent cell death of infected cells.

292 For macrophages, cell death is considered as a defense mechanism against infection (Chow et

293 al., 2016). Indeed, pyroptosis of infected macrophages permits the spread of inflammatory

294 mediators such as IL-1 $\beta$. Thus, for intracellular bacteria, many of which infect macrophages

295 (Mitchell et al., 2016), the death of their host cell is an obstacle as their cellular replication

296 niche is destroyed. Therefore, while bacterial-induced reduction of OXPHOS might be

297 beneficial for intracellular bacteria to obtain host cell resources, they need to counterbalance

298 the consequences of OXPHOS cessation, i.e. the collapse of the mitochondrial $\Delta \psi_{\mathrm{m}}$ and

299 subsequent cell death, to preserve their replication niches.

300 We have previously shown that the L. pneumophila T4SS effector MitF is implicated in fragmenting the mitochondrial networks of infected macrophages. These changes in the mitochondrial dynamics have a profound impact on OXPHOS that was severely impaired and accompanied by increased glycolysis in Legionella-infected cells (Escoll et al., 2017b). Here

304 we show that, despite the impairment of mitochondrial respiration in infected cells, 305 L. pneumophila conserves the $\Delta \psi_{\mathrm{m}}$ of host cells by inducing the "reverse mode" of the $\mathrm{F}_{\mathrm{O}} \mathrm{F}_{1}$ 306 ATPase by a mechanism that is T4SS-dependent and partially mediated by the T4SS effector 307 LpSpl. When translocated into human cells, the S1P-lyase activity of L. pneumophila LpSpl 308 reduces S1P levels in infected cells and restrains autophagy, likely because S1P is involved in the initiation of autophagosome formation at MAMs (Rolando et al., 2016).

310 How $L p S p l$ may regulate the activity of the $\mathrm{F}_{\mathrm{O}} \mathrm{F}_{1}$-ATPase is an interesting question. Indeed, 311 phosphorylated lipids are critical regulators of mitochondrial functions and S1P is a potent lipid 312 mediator that regulates various physiological processes as well as diverse mitochondrial 313 functions such as mitochondrial respiration, ETC functioning or mitochondrial-dependent cell 314 death (Hernández-Corbacho et al., 2017; Nielson and Rutter, 2018). Furthermore it was 
reported that S1P interaction with Prohibitin 2 (PHB2) regulates ETC functioning and mitochondrial respiration (Strub et al., 2011) and that a link between PHB2, ETC functioning and the activation of "mitoflashes" (Jian et al., 2017) exists, which are dynamic and transient uncouplings of mitochondrial respiration from ATP production that are partially dependent on the "reverse mode" of the $F_{O} F_{1}$-ATPase (Wei-LaPierre and Dirksen, 2019). Thus, it is possible that $L p \mathrm{Spl}$ modulates mitochondrial S1P levels helping the induction of the "reverse mode" of the mitochondrial $\mathrm{F}_{\mathrm{O}} \mathrm{F}_{1}-\mathrm{ATPase}$ by involving PHB2, ETC complex assembly or the generation of mitoflashes, a fascinating possibility that we will further investigate.

The regulation of host cell death by intracellular bacteria is widely studied (Rudel et al., 2010). For L. pneumophila, T4SS effectors activating and inhibiting cell death of infected cells have been described (Speir et al., 2014), suggesting that a very delicate interplay of positive and negative signals governs the fate of infected macrophages. Here we have shown that bacterial replication occurs preferentially in those infected macrophages that are able to conserve the $\Delta \psi_{\mathrm{m}}$ and delay cell death, a condition that is difficult to achieve in the absence of mitochondrial respiration. Thus, the manipulation of the activity of the mitochondrial $\mathrm{F}_{\mathrm{O}} \mathrm{F}_{1}$ ATPase by L. pneumophila, which allows this pathogen to use the ATP hydrolase activity to pump $\mathrm{H}^{+}$to the IMS to maintain the $\Delta \psi_{\mathrm{m}}$ in infected cells, is a novel virulence strategy that might contribute to the fine-tuning of the timing of host cell death during bacterial infection.

MATERIALS and METHODS

\section{Human Primary Cell Cultures}

Human blood was collected from healthy volunteers under the ethical rules established by the French National Blood Service (EFS). Peripheral blood mononuclear cells (PBMCs) were isolated by Ficoll-Hypaque density-gradient separation (Lympholyte-H; Cedarlane Laboratories) at room temperature. PBMCs were incubated with anti-human CD14 antibodies coupled to magnetic beads (Miltenyi Biotec) and subjected to magnetic separation using LS columns (Miltenyi Biotec). Positive selected CD14 ${ }^{+}$cells were counted and CD14 expression was analysed by flow cytometry, repeatedly showing a purity $>90 \%$. CD14 cells were plated in RPMI 1640 medium (Life Technologies) supplemented with 10\% heat-inactivated fetal bovine serum (FBS, Biowest) in 6 well multi-dish Nunc UpCell Surface cell culture plates or $10 \mathrm{~cm}$ Nunc UpCell Surface cell culture dishes (Thermo Fisher) and differentiated to human monocyte-derived macrophages (hMDMs) by incubation with $100 \mathrm{ng} / \mathrm{ml}$ of recombinant human macrophage colony-stimulating factor (rhMCSF, Miltenyi Biotec) for 6 days at $37^{\circ} \mathrm{C}$ 
After 6 days differentiation, UpCell plates were placed at $20^{\circ} \mathrm{C}$ during 10 minutes and hMDMs were gently detached, counted and plated in RPMI 1640 10\% FBS in 384-well plates (Greiner

350 Bio-One).

\section{Bacterial strains and mutant construction}

L. pneumophila strain Paris or JR32 and their derivatives were grown for 3 days on N-(2acetamido)-2-amino-ethanesulfonic acid (ACES)-buffered charcoal-yeast (BCYE) extract agar, at $37^{\circ} \mathrm{C}$. For eGFP-expressing strains harbouring pNT28 plasmid (Tiaden et al., 2007), chloramphenicol (Cam; $5 \mu \mathrm{g} / \mathrm{mL}$ ) was added. Knock-out mutant strains of L. pneumophila genes coding for the T4SS effectors $L p S p l$ and MitF/LegG1 were previously described (Escoll et al., 2017b; Rolando et al., 2016; Rothmeier et al., 2013). The knock-out mutant strain of the L. pneumophila gene coding for the effector LncP was constructed as previously described (Brüggemann et al., 2006; Rolando et al., 2016). In brief, the gene of interest was inactivated by introduction of an apramycine resistance (apraR) cassette into the chromosomal gene by 3steps PCR. The g primers used for the $\operatorname{lnc} P$ (lpp2981) knock out mutant are: LncP_F: ACCCTGGTTCATGGTAACAATGG; LncP_Inv_R: GAGCGGATCGGGGATTGTCTTATCAGGCGAATGGTGTGAAAGG; LncP_Inv_F: AATCAGATGGGTAAGCCGATTGG. To amplify the apramycine cassette, the primers Apra_F: TTCATGTGCAGCTCCATCAGC and Apra_R: AAGACAATCCCCGATCCGCTC were used.

\section{Infection of hMDMs and automatic confocal imaging}

hMDMs were infected with L. pneumophila grown for three days on BCYE agar plates. Bacteria were dissolved in 1X PBS (Life Technologies), the optical density (OD) was adjusted to $\mathrm{OD}_{600}$ of $2.5\left(2.2 \times 10^{9}\right.$ bacteria $\left./ \mathrm{mL}\right)$ and the bacteria were then further diluted in serum-free XVIVO-15 medium (Lonza) prior to infection to obtain the respective multiplicity of infection (MOI). hMDMs were washed twice with serum-free XVIVO-15 medium and then infected $(\mathrm{MOI}=10)$ with $25 \mu \mathrm{L}$ of bacteria in 384-well plates (Greiner Bio-One). The infection was synchronized by centrifugation ( $200 \mathrm{~g}$ for $5 \mathrm{~min}$ ) and the infected cells were incubated at $37^{\circ} \mathrm{C}$ for $5 \mathrm{~min}$ in a water bath and then for $25 \mathrm{~min}$ at $37^{\circ} \mathrm{C} / 5 \% \mathrm{CO}_{2}$. After three intensive washes with serum-free XVIVO-15 medium, the infection proceeded in serum-free XVIVO-15 medium for the respective time points. 30 min prior imaging, $25 \mu \mathrm{L}$ of culture medium were removed and replaced by $25 \mu \mathrm{L}$ of $2 \mathrm{X}$ mix of dyes, to a final concentration of $200 \mathrm{ng} / \mathrm{mL}$ of Hoechst H33342 (nuclear staining; Life Technologies), $10 \mathrm{nM}$ of TMRM (mitochondrial 
381

382

383

384

385

386

387

388

389

390

391

392

393

394

395

396

397

398

399

400

401

402

403

404

405

406

407

408

409

410

411

412

413

membrane potential; Life Technologies), and/or 1/100 Annexin-V-Alexa Fluor 647 (early apoptosis; Life Technologies). If chemical inhibitors of the Electron Transport Chain (ETC) were used in the experiments, they were added to hMDMs at the indicated times points at the following concentrations: $5 \mu \mu \mathrm{M}$ Oligomycin (Enzo), $100 \quad \mu \mathrm{M} \quad$ DCCD (Dicyclohexylcarbodiimide, Sigma), $10 \mu \mathrm{M}$ FCCP (Tocris), $50 \mu \mathrm{M}$ BTB06584 (Sigma). Image acquisitions of multiple fields (9 to 25) per well were performed on an automated confocal microscope (OPERA Phenix, Perkin Elmer) using 60X objective, excitation lasers at 405, 488, 561 and $640 \mathrm{~nm}$, and emission filters at 450, 540, 600 and $690 \mathrm{~nm}$, respectively.

\section{Metabolic Extracellular Flux Analysis}

hMDMs $(50,000)$ were plated in XF-96-cell culture plates (Seahorse Bioscience). For OCR measurements, XF Assay Medium (Seahorse Bioscience) supplemented with $1 \mathrm{mM}$ pyruvate and $10 \mathrm{mM}$ glucose was used, and OCR was measured in a XF-96 Flux Analyzer (Seahorse Bioscience). For the mitochondrial respiratory control assay, hMDMs were infected at MOI = 10 and at 6 hpi., different drugs were injected (Mitostress kit, Seahorse Bioscience) while OCR was monitored. Specifically, Olygomycin was injected through the port A, then FCCP was injected through the port B, and finally Rotenone + Antimycin A were injected through the port $\mathrm{C}$, to reach each of the drugs a final concentration in the well of $0.5 \mu \mathrm{M}$.

\section{Automatic High-Content Analyses (HCA)}

All analyses were performed with Harmony software v.4.9 (Perkin Elmer) using in-house developed scripts (available upon request). For the HCA of the mitochondrial membrane potential $\left(\Delta \psi_{\mathrm{m}}\right)$, the Hoechst signal was used to segment nuclei in the 405/450 channel (excitation/emission), Hoechst background signal in the cytoplasm was used to segment the cytoplasm region in the 405/450 channel, L. pneumophila was identified by measuring the GFP signal in the 488/540 channel, and TMRM (10 nM) signal in the 561/600 channel was used to measure $\Delta \psi_{\mathrm{m}}$ by calculating SD/Mean TMRM intensity values in each infected and noninfected cell. For the HCA of cell death, the Hoechst signal was used to segment nuclei in the 405/450 channel, Hoechst background signal in the cytoplasm was used to segment the cytoplasm region, and the identification of L. pneumophila was performed using the GFP signal in the 488/540 channel. Then, Annexin-V-AlexaFluor 647 signal was measured in the 640/690 channel and the Hoechst signal intensity was measured in the 405/450 channel for each infected or non-infected cell. For the HCA analyses combining $\Delta \psi_{\mathrm{m}}$ and cell death, both HCA strategies aforementioned were merged, using high Hoechst signal in the 405/450 channel to segment nuclei, low Hoechst signal in the 405/450 channel to segment cytoplasm, GFP signal in the 
$414488 / 540$ channel to identify bacteria, TMRM signal in the 561/600 channel to measure $\Delta \psi_{\mathrm{m}}$

415 (SD/Mean) and Annexin-V-AlexaFluor 647 signal in the 640/690 channel to measure cell

416 death.

\section{Whole genome sequencing for mutant validation}

418 Chromosomal DNA was extracted from BCYE-grown L. pneumophila using the DNeasy Blood 419 and Tissue Kit (Qiagen). The Illumina NGS libraries were prepared using the Nextera DNA 420 Flex Library Prep following the manufacturer's instructions (Illumina Inc.). High-throughput 421 sequencing was performed with a MiSeq Illumina sequencer $(2 \times 300 \mathrm{bp}$, Illumina Inc.) by the 422 Biomics Pole (Institut Pasteur). For the analysis, we first removed adapters from Illumina sequencing reads using Cutadapt software version 1.15 (Martin, 2011) and we used Sickle 424 (https://github.com/najoshi/sickle) with a quality threshold of 20 (Phred score) to trim bad quality extremities. Reads were assembled using Spades (Nurk et al., 2013) and different Kmer values. The region corresponding to the gene of interest was identified by blastn, extracted, and compared to the homologous region in the L. pneumophila strain Paris WT genome and to the antibiotic cassette sequence using blastn. The results are visually inspected with ACT (Artemis Comparison Tool) (Carver et al., 2005). In addition, we searched the entire genome whether off-target mutations had occurred, using Bowtie 2 (Langmead and Salzberg, 2012) to perform a mapping against the genome sequence of L. pneumophila strain Paris (NC_006368.1). SNPs and small indels were searched for with freebayes SNP caller (Garrison and Marth, 2012), mutations and small indels were visualized in the Artemis genome viewer (Carver et al., 2005) to analyze them (new amino acid, synonymous mutation, frameshifts, etc). We used Samtools to find regions with no coverage (or close to zero) (Li et al., 2009). Regions or positions with such anomalies were visualized and compared with the corresponding region of the assembly. This confirmed that no off-target mutations impacting the phenotype of the mutant had occurred.

\section{Statistical analyses}

440 The two-sample Student's t-test (Mann-Whitney $U$ test, non-assumption of Gaussian 441 distributions) was used in all data sets unless stated otherwise. Data analysis was performed using Prism v9 (Graphpad Software).

\section{AUTHOR CONTRIBUTIONS}

444 PE conceived the study; PE, LP, MD and SS prepared blood-derived human cells and/or 445 performed experiments; TS constructed bacterial mutants; PE, LP and CR analyzed data; PE 446 and $\mathrm{CB}$ provided funding; $\mathrm{CB}$ provided critical advice; PE and CB wrote the manuscript. 
447

448

449

450

451

452

453

454

455

456

457

458

459

460

461

462

463

464

465

466

467

468

469

470

471

472

473

474

475

476

477

478

479

480

481

482

483

484

485

486

487

488

\section{ACKNOWLEDGEMENTS}

We acknowledge C.B.'s, P. Glaser's lab members and F. Stavru at Institut Pasteur for fruitful discussions. We thank N. Aulner, A. Danckaert, Photonic BioImaging (PBI) UTechS and M. Hassan, Center for Translational Science (CRT) at Institut Pasteur, for support. This research was funded by the Institut Pasteur, DARRI - Institut Carnot - Microbe et santé (grant number INNOV-SP10-19) to PE; the Agence National de Recherche (grant number ANR-10-LABX62-IBEID) and the Fondation de la Recherché Médicale (FRM) (grant number EQU201903007847) to CB, and the Région Ile-de-France (program DIM1Health) to PBI (part of FranceBioImaging, ANR-10-INSB-04-01). MD was supported by the Ecole Doctorale FIRE - "Programme Bettencourt". SS was supported by the Pasteur Paris-University (PPU) International PhD Program.

\section{REFERENCES}

Bock FJ, Tait SWG. 2020. Mitochondria as multifaceted regulators of cell death. Nat Rev Mol Cell Biol 21:85-100. doi:10.1038/s41580-019-0173-8

Brand MD, Nicholls DG. 2011. Assessing mitochondrial dysfunction in cells. Biochem J 435:297-312. doi:10.1042/BJ20110162

Brüggemann H, Hagman A, Jules M, Sismeiro O, Dillies M-A, Gouyette C, Kunst F, Steinert M, Heuner K, Coppée J-Y, Buchrieser C. 2006. Virulence strategies for infecting phagocytes deduced from the in vivo transcriptional program of Legionella pneumophila. Cell Microbiol 8:1228-1240. doi:10.1111/j.1462-5822.2006.00703.x

Carver TJ, Rutherford KM, Berriman M, Rajandream M-A, Barrell BG, Parkhill J. 2005. ACT: the Artemis Comparison Tool. Bioinformatics 21:3422-3423. doi:10.1093/bioinformatics/bti553

Chow SH, Deo P, Naderer T. 2016. Macrophage cell death in microbial infections. Cellular Microbiology 18:466-474. doi:https://doi.org/10.1111/cmi.12573

Connolly NMC, Theurey P, Adam-Vizi V, Bazan NG, Bernardi P, Bolaños JP, Culmsee C, Dawson VL, Deshmukh M, Duchen MR, Düssmann H, Fiskum G, Galindo MF, Hardingham GE, Hardwick JM, Jekabsons MB, Jonas EA, Jordán J, Lipton SA, Manfredi G, Mattson MP, McLaughlin B, Methner A, Murphy AN, Murphy MP, Nicholls DG, Polster BM, Pozzan T, Rizzuto R, Satrústegui J, Slack RS, Swanson RA, Swerdlow RH, Will Y, Ying Z, Joselin A, Gioran A, Moreira Pinho C, Watters O, Salvucci M, Llorente-Folch I, Park DS, Bano D, Ankarcrona M, Pizzo P, Prehn JHM. 2018. Guidelines on experimental methods to assess mitochondrial dysfunction in cellular models of neurodegenerative diseases. Cell Death Differ 25:542-572. doi:10.1038/s41418-017-0020-4

Degtyar E, Zusman T, Ehrlich M, Segal G. 2009. A Legionella effector acquired from protozoa is involved in sphingolipids metabolism and is targeted to the host cell mitochondria. Cell Microbiol 11:1219-1235. doi:10.1111/j.1462-5822.2009.01328.x

Dolezal P, Aili M, Tong J, Jiang J-H, Marobbio CM, Lee S fung, Schuelein R, Belluzzo S, Binova E, Mousnier A, Frankel G, Giannuzzi G, Palmieri F, Gabriel K, Naderer T, Hartland EL, Lithgow T. 2012. Legionella pneumophila Secretes a Mitochondrial Carrier Protein during Infection. PLoS Pathogens 8. doi:10.1371/journal.ppat.1002459 
bioRxiv preprint doi: https://doi.org/10.1101/2021.05.12.443790; this version posted May 14, 2021. The copyright holder for this preprint (which was not certified by peer review) is the author/funder, who has granted bioRxiv a license to display the preprint in perpetuity. It is made available under aCC-BY-NC-ND 4.0 International license.

Duchen MR, Surin A, Jacobson J. 2003. [17] Imaging mitochondrial function in intact cellsMethods in Enzymology, Biophotonics, Part B. Academic Press. pp. 353-389. doi:10.1016/S0076-6879(03)61019-0

Escoll P, Buchrieser C. 2019. Metabolic reprogramming: an innate cellular defence mechanism against intracellular bacteria? Current Opinion in Immunology 60:117-123. doi:10.1016/j.coi.2019.05.009

Escoll P, Buchrieser C. 2018. Metabolic reprogramming of host cells upon bacterial infection: Why shift to a Warburg-like metabolism? FEBS $J$ 285:2146-2160. doi:10.1111/febs.14446

Escoll P, Rolando M, Buchrieser C. 2017a. MAMs are attractive targets for bacterial repurposing of the host cell: MAM-functions might be key for undermining an infected cell. Bioessays 39. doi:10.1002/bies.201600171

Escoll P, Song O-R, Viana F, Steiner B, Lagache T, Olivo-Marin J-C, Impens F, Brodin P, Hilbi H, Buchrieser C. 2017b. Legionella pneumophila Modulates Mitochondrial Dynamics to Trigger Metabolic Repurposing of Infected Macrophages. Cell Host \& Microbe 22:302-316.e7. doi:10.1016/j.chom.2017.07.020

Gandhi S, Wood-Kaczmar A, Yao Z, Plun-Favreau H, Deas E, Klupsch K, Downward J, Latchman DS, Tabrizi SJ, Wood NW, Duchen MR, Abramov AY. 2009. PINK1Associated Parkinson's Disease Is Caused by Neuronal Vulnerability to CalciumInduced Cell Death. Molecular Cell 33:627-638. doi:10.1016/j.molcel.2009.02.013

Garrison E, Marth G. 2012. Haplotype-based variant detection from short-read sequencing. arXiv:12073907 [q-bio].

Hernández-Corbacho MJ, Salama MF, Canals D, Senkal CE, Obeid LM. 2017. Sphingolipids in mitochondria. Biochimica et Biophysica Acta (BBA) - Molecular and Cell Biology of Lipids 1862:56-68. doi:10.1016/j.bbalip.2016.09.019

Ivanes F, Faccenda D, Gatliff J, Ahmed AA, Cocco S, Cheng CHK, Allan E, Russell C, Duchen MR, Campanella M. 2014. The compound BTB06584 is an IF1-dependent selective inhibitor of the mitochondrial F1Fo-ATPase. British Journal of Pharmacology 171:4193-4206. doi:10.1111/bph.12638

Jian C, Xu F, Hou T, Sun T, Li J, Cheng H, Wang X. 2017. Deficiency of PHB complex impairs respiratory supercomplex formation and activates mitochondrial flashes. J Cell Sci 130:2620-2630. doi:10.1242/jcs. 198523

Langmead B, Salzberg SL. 2012. Fast gapped-read alignment with Bowtie 2. Nat Methods 9:357-359. doi:10.1038/nmeth.1923

Li H, Handsaker B, Wysoker A, Fennell T, Ruan J, Homer N, Marth G, Abecasis G, Durbin R, 1000 Genome Project Data Processing Subgroup. 2009. The Sequence Alignment/Map format and SAMtools. Bioinformatics 25:2078-2079. doi:10.1093/bioinformatics/btp352

Martin M. 2011. Cutadapt removes adapter sequences from high-throughput sequencing reads. EMBnet.journal 17:10-12. doi:10.14806/ej.17.1.200

Mitchell G, Chen C, Portnoy DA. 2016. Strategies Used by Bacteria to Grow in Macrophages. Microbiology Spectrum 4. doi:10.1128/microbiolspec.MCHD-0012-2015

Mondino S, Schmidt S, Rolando M, Escoll P, Gomez-Valero L, Buchrieser C. 2020. Legionnaires' Disease: State of the Art Knowledge of Pathogenesis Mechanisms of Legionella. Annu Rev Pathol Mech Dis 15:439-466. doi:10.1146/annurevpathmechdis-012419-032742

Nielson JR, Rutter JP. 2018. Lipid-mediated signals that regulate mitochondrial biology. J Biol Chem 293:7517-7521. doi:10.1074/jbc.R117.001655

Nurk S, Bankevich A, Antipov D, Gurevich AA, Korobeynikov A, Lapidus A, Prjibelski AD, Pyshkin A, Sirotkin A, Sirotkin Y, Stepanauskas R, Clingenpeel SR, Woyke T, McLean JS, Lasken R, Tesler G, Alekseyev MA, Pevzner PA. 2013. Assembling single-cell 
genomes and mini-metagenomes from chimeric MDA products. J Comput Biol 20:714 737. doi:10.1089/cmb.2013.0084

O'Neill LAJ, Pearce EJ. 2016. Immunometabolism governs dendritic cell and macrophage function. $J$ Exp Med 213:15-23. doi:10.1084/jem.20151570

Rolando M, Escoll P, Nora T, Botti J, Boitez V, Bedia C, Daniels C, Abraham G, Stogios PJ, Skarina T, Christophe C, Dervins-Ravault D, Cazalet C, Hilbi H, Rupasinghe TWT, Tull D, McConville MJ, Ong SY, Hartland EL, Codogno P, Levade T, Naderer T, Savchenko A, Buchrieser C. 2016. Legionella pneumophila S1P-lyase targets host sphingolipid metabolism and restrains autophagy. Proc Natl Acad Sci USA 113:19011906. doi:10.1073/pnas.1522067113

Rothmeier E, Pfaffinger G, Hoffmann C, Harrison CF, Grabmayr H, Repnik U, Hannemann M, Wölke S, Bausch A, Griffiths G, Müller-Taubenberger A, Itzen A, Hilbi H. 2013. Activation of Ran GTPase by a Legionella effector promotes microtubule polymerization, pathogen vacuole motility and infection. PLoS Pathog 9:e1003598. doi:10.1371/journal.ppat.1003598

Rudel T, Kepp O, Kozjak-Pavlovic V. 2010. Interactions between bacterial pathogens and mitochondrial cell death pathways. Nat Rev Microbiol 8:693-705. doi:10.1038/nrmicro2421

Russell DG, Huang L, VanderVen BC. 2019. Immunometabolism at the interface between macrophages and pathogens. Nat Rev Immunol 19:291-304. doi:10.1038/s41577-0190124-9

Siegl C, Prusty BK, Karunakaran K, Wischhusen J, Rudel T. 2014. Tumor Suppressor p53 Alters Host Cell Metabolism to Limit Chlamydia trachomatis Infection. Cell Reports 9:918-929. doi:10.1016/j.celrep.2014.10.004

Singh V, Jamwal S, Jain R, Verma P, Gokhale R, Rao KVS. 2012. Mycobacterium tuberculosisDriven Targeted Recalibration of Macrophage Lipid Homeostasis Promotes the Foamy Phenotype. Cell Host \& Microbe 12:669-681. doi:10.1016/j.chom.2012.09.012

Speir M, Vince JE, Naderer T. 2014. Programmed cell death in Legionella infection. Future Microbiology 9:107-118. doi:10.2217/fmb.13.139

Spier A, Stavru F, Cossart P. 2019. Interaction between Intracellular Bacterial Pathogens and Host Cell Mitochondria. Microbiology Spectrum 7:BAI-0016-2019.

Strub GM, Paillard M, Liang J, Gomez L, Allegood JC, Hait NC, Maceyka M, Price MM, Chen Q, Simpson DC, Kordula T, Milstien S, Lesnefsky EJ, Spiegel S. 2011. Sphingosine-1phosphate produced by sphingosine kinase 2 in mitochondria interacts with prohibitin 2 to regulate complex IV assembly and respiration. FASEB $j$ 25:600-612. doi:10.1096/fj.10-167502

Tiaden A, Spirig T, Weber SS, Brüggemann H, Bosshard R, Buchrieser C, Hilbi H. 2007. The Legionella pneumophila response regulator LqsR promotes host cell interactions as an element of the virulence regulatory network controlled by RpoS and LetA. Cell Microbiol 9:2903-2920. doi:10.1111/j.1462-5822.2007.01005.x

Wei-LaPierre L, Dirksen RT. 2019. Isolating a reverse-mode ATP synthase-dependent mechanism of mitoflash activation. Journal of General Physiology 151:708-713. doi:10.1085/jgp.201912358 
FIGURE LEGENDS

Figure 1. Despite a reduction of oxidative phosphorylation (OXPHOS), hMDMs maintain uninfected (Non-infected). At 6 hours post-infection (hpi), a cellular respiratory control assay was performed by measuring oxygen consumption rate (OCR) during the sequential addition of mitochondrial respiratory inhibitors (see also Figure S1A). (B) Basal respiration of hMDMs in the same conditions as in (A), at 6 hpi. (C) hMDMs were infected as in (A) with GFPexpressing bacteria (green), nuclei of host cells were stained with Hoechst (Nuc, blue) and $\Delta \psi_{\mathrm{m}}$ was monitored from 1 to 12 hpi using TMRM dye in non-quenching conditions (10 $\mathrm{nM})$. Representative confocal microscope images of non-infected and infected cells at 3, 6, 9 and 12 hpi are shown. Intracellular bacterial replication can be observed in Lpp-WT infected hMDMs $\mathrm{SD} / \mathrm{Mean})$ in the assays described in (C). Data from 4 independent experiments with a total of 10 replicates (E) Single-cell analysis at 6 hpi of the assays described in (C). Single-cell data from a representative experiment (full time-course in Figure $\mathrm{S} 1 \mathrm{C}$ ) $* * \mathrm{p}$-value $<0.01$; *** pvalue $<0.00001 ;$ ns $=$ non-significant (Mann-Whitney $U$ test $)$. $\Delta \psi_{\mathrm{m}}$ generated by the Electron Transport Chain is used by the $\mathrm{F}_{\mathrm{O}} \mathrm{F}_{1}$-ATPase to synthesize ATP. The "reverse mode" of the $\mathrm{F}_{\mathrm{O}} \mathrm{F}_{1}$-ATPase leads to ATP hydrolysis to pump $\mathrm{H}^{+}$to the intermembrane space (IMS). IMM: inner mitochondrial membrane. (B) When the $\mathrm{F}_{0} \mathrm{~F}_{1}$-ATPase is inhibited by Oligomycin or DCCD, an increase in $\Delta \psi_{\mathrm{m}}$ indicates that the ATPase was working in the "forward mode" $\left(\mathrm{H}^{+}\right.$accumulate in the IMS), while a decrease in $\Delta \psi_{\mathrm{m}}$ indicates functioning in the "reverse mode" $\left(\mathrm{H}^{+}\right.$cannot be translocated to the IMS by the $\mathrm{F}_{\mathrm{O}} \mathrm{F}_{1}$-ATPase to sustain the $\Delta \psi_{\mathrm{m}}$ ). (C) hMDMs were infected with GFP-expressing bacteria (green), or left uninfected (Non-infected). At 5.5 hpi cells were labeled with Hoechst to identify the cell nucleus (Nuc, blue) and TMRM (red) to quantify $\Delta \psi_{\mathrm{m}}$. At $6 \mathrm{hpi}$, addition of medium (no 613 changes) or FCCP (complete depolarization) was used as controls. Representative confocal 614 images of Lpp-WT-infected hMDMs (6 hpi) at $5 \mathrm{~min}$ before the addition of medium (top) or 615 FCCP (bottom), and at 5, 25 and 50 min after addition of medium or FCCP. Bar: $20 \mu \mathrm{m}$. (D) 616 Quantification of (C) before (baseline) and after the addition of medium. Each dot represents 617 mean \pm SD of 3 independent experiments with a total of 8 replicates. (E) Same as (D) but FCCP 
was added. (F) Same as (D) but oligomycin was added. (G) Same as (D) but DCCD was added. (H) Same as (C) but infection was performed with Lpp-WT, Lpp- $\Delta d o t A$, Lpp- $\Delta l n c P$, Lpp- $\Delta s p l$, L. pneumophila strain Philadelphia JR32 (JR32)-WT, JR32- $\Delta i c m T$ or JR32- $\Delta m i t F$. TMRM values (SD/Mean) at $50 \mathrm{~min}$ after DCCD addition are shown. Data from a minimum of 3 experiments per strain with 10 or more replicates per strain $* *$ p-value $<0.01$; *** p-value $<$ $0.001 ; * * * * p$-value $<0.00001 ; \mathrm{ns}=$ non-significant $($ Mann-Whitney $U$ test $)$

Figure 3. Inhibition of the "reverse mode" of mitochondrial $\mathrm{F}_{\mathrm{O}} \mathrm{F}_{1}$ ATPase reduces the $\Delta \psi_{\mathrm{m}}$ of L. pneumophila-infected hMDMs. (A) hMDMs were infected with GFP-expressing bacteria (green), Lpp-WT or Lpp- $\Delta d o t A$, or left uninfected (Non-infected). At 5.5 hpi cells were labeled with Hoechst to identify cell nucleus (Nuc, blue) and TMRM (red) to quantify $\Delta \psi_{\mathrm{m}}$. At 6 hpi, BTB06584 (BTB, $50 \mu \mathrm{M})$, a specific inhibitor of the "reverse mode" of the ATPase, was added and $\Delta \psi_{\mathrm{m}}$ monitored. Representative confocal microscopy images of non-infected (top) and Lpp-WT-infected (bottom) hMDMs (6 hpi) at $5 \mathrm{~min}$ before the addition and at 5, 25 and 50 min after the addition of BTB. Bar: $20 \mu \mathrm{m}$. (B) Quantification of (C) before (baseline) and after the addition of BTB. Each dot represents the mean \pm SD of 3 independent experiments with a total of 6 replicates. (C) Same infection conditions than (A) but TMRM values (SD/Mean) at 50 min after BTB addition are shown. Data from 3 experiments with a total of 6 hMDMs treated with BTB $(50 \mu \mathrm{M})$ or left untreated (non-treated). Single-cell data from one representative experiment ${ }^{*} \mathrm{p}$-value $<0.05 ; * * \mathrm{p}$-value $<0.01$; ns $=$ non-significant (MannWhitney $U$ test)

Figure 4. Inhibition of $F_{0}-F_{1}$ ATPase "reverse mode" increases cell death in non-treated or treated with $50 \mu \mathrm{M}$ BTB. The presence of GFP-expressing bacteria in each cell was monitored and the number of infected cells in the whole population was graphed as percentage of infected cells. Data from 3 independent experiments with a total of 7 replicates per condition and time-point (B) hMDMs were infected with Lpp-WT-GFP (green), the nuclei of host cells were stained with Hoechst (Nuc, blue) and Annexin-V Alexa Fluor 647 was added to the cell culture to monitor early cell death (Annexin, yellow) from 1 to 18 hpi in non-treated or BTB-treated hMDMs. Representative confocal images of non-treated and Lpp-WT-GFPinfected cells at 6,12 and 18 hpi are shown. Intracellular bacterial replication can be observed in non-treated Lpp-WT infected hMDMs at 12 and 18 hpi. Bar: $20 \mu \mathrm{m}$. (C) hMDMs stained as 
650 in (B) were infected with Lpp-WT-GFP or left uninfected (Non-infected), and then were treated 651 or not with BTB $(50 \mu \mathrm{M})$. Percentage of Annexin- $\mathrm{V}^{+}$cells at 24 hpi is shown. Data from 3 652 independent experiments with a total of 7 replicates per condition (D) Single-cell analysis (12 653 hpi) of Annexin-V intensity of the assays described in (B). Single-cell data from one 654 representative experiment (18 hpi shown in Figure S2A) (E) hMDMs were infected with Lpp655 WT-GFP, nuclei of host cells were stained with Hoechst, and TMRM and Annexin-V Alexa 656 Fluor 647 were added to the cells to simultaneously monitor (1-18 hpi) $\Delta \psi_{\mathrm{m}}$ and early cell death, 657 respectively, in non-treated or BTB-treated hMDMs (representative multi-field confocal 658 images in Figure S2C). Single-cell analyses (12 hpi) of $\Delta \psi_{\mathrm{m}}$ (TMRM SD/Mean) and cell death 659 (Annexin-V intensity) in more than 1600 cells per condition are shown. Single-cell data from 660 one representative experiment; Green dots: Non-treated Lpp-WT-infected single cells. Orange 661 dots: BTB-treated Lpp-WT-infected single cells. (F) Same infection conditions as in (E) but 662 vacuole size was monitored in each Lpp-WT-infected single cell. Single-cell analyses (12 hpi) 663 of $\Delta \psi_{\mathrm{m}}$ (TMRM SD/Mean), vacuole size $\left(\mu \mathrm{m}^{2}\right)$, and cell death (Annexin-V intensity) in more 664 than 3800 cells are shown. Single-cell data from one representative experiment; Color scale 665 (yellow) represents Annexin V intensity per cell (AU). (G) Same as in (F) at 18 hpi. *p-value $666<0.05 ; * *$ p-value $<0.01 ; * * *$ p-value $<0.001 ; * * * *$ p-value $<0.00001 ;$ ns $=$ non-significant 667 (Mann-Whitney $U$ test) 
bioRxiv preprint doi: $\mathrm{https}$ ://doi.org/10.1101/2021.05.12.443790; this version posted May 14, 2021. The copyright holder for this preprint
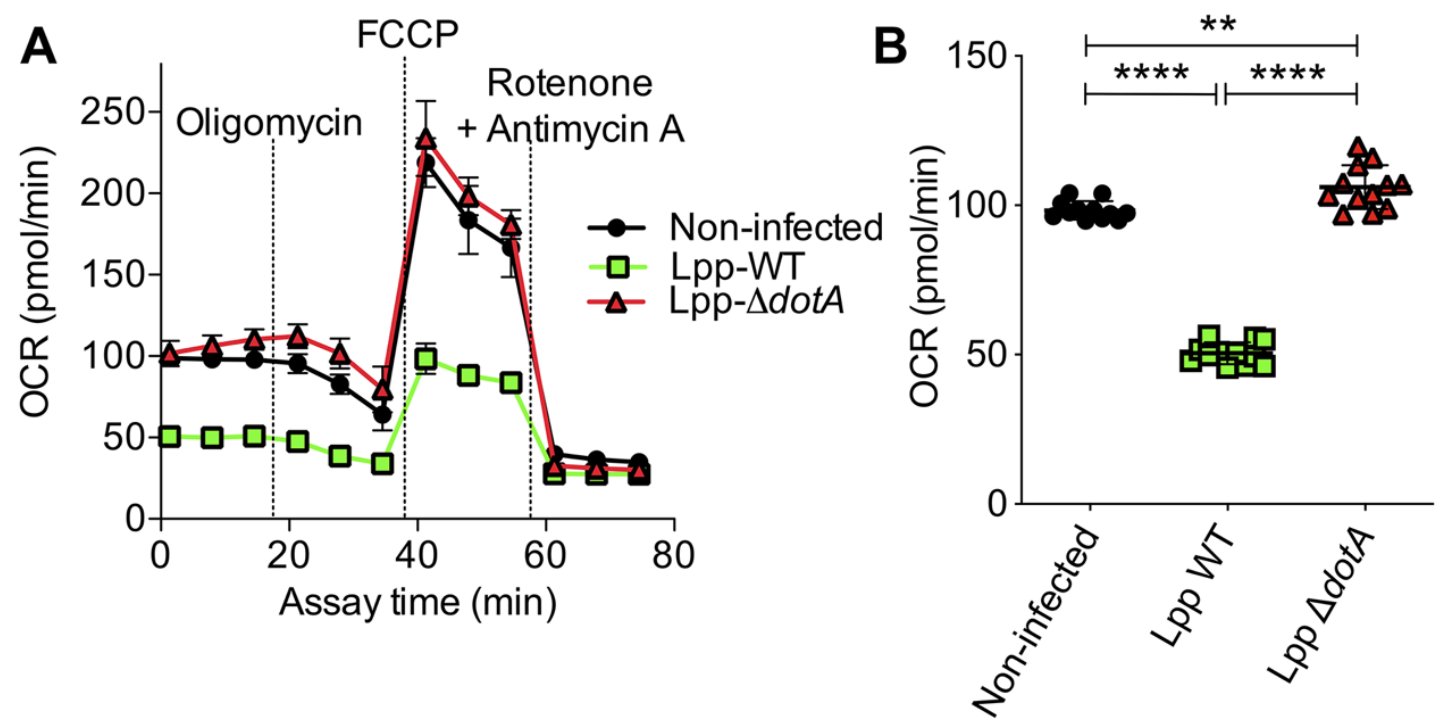

C

3 h.p.i

6 h.p.i

9 h.p.i

12 h.p.i

Non-infected
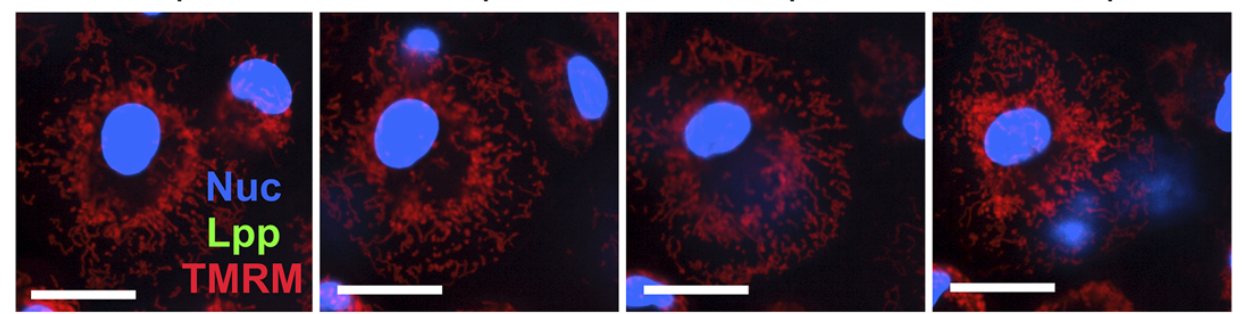

Lpp WT
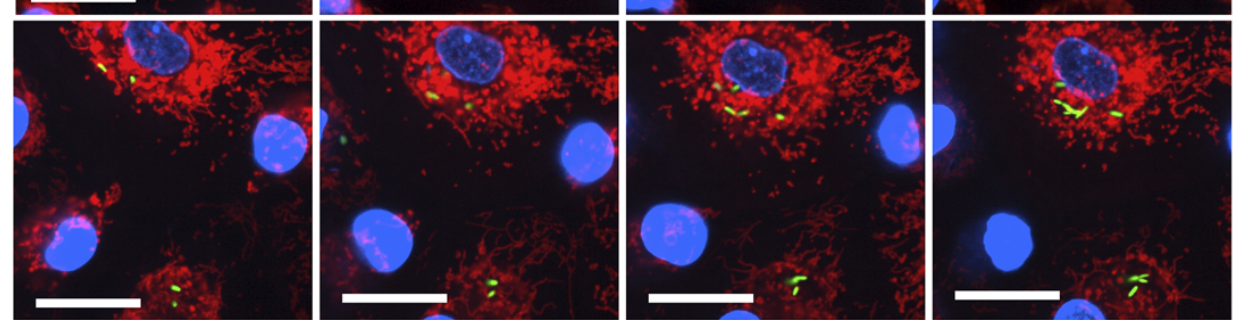

$\operatorname{Lpp} \Delta \operatorname{dot} A$
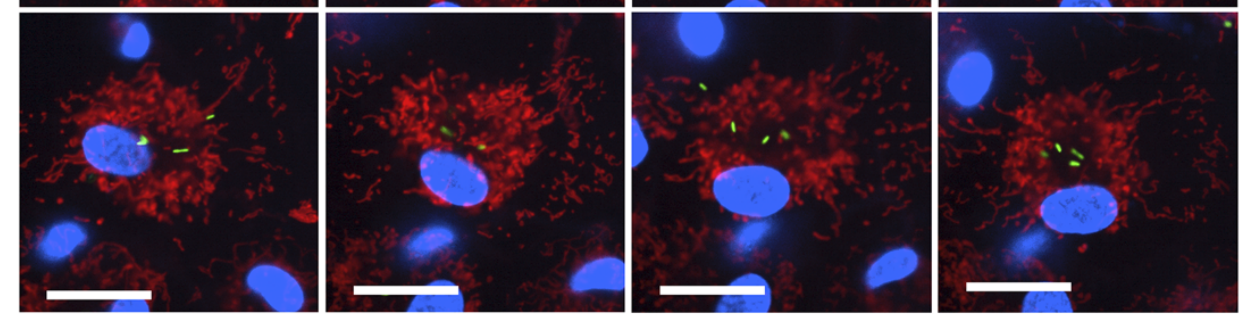

D

E

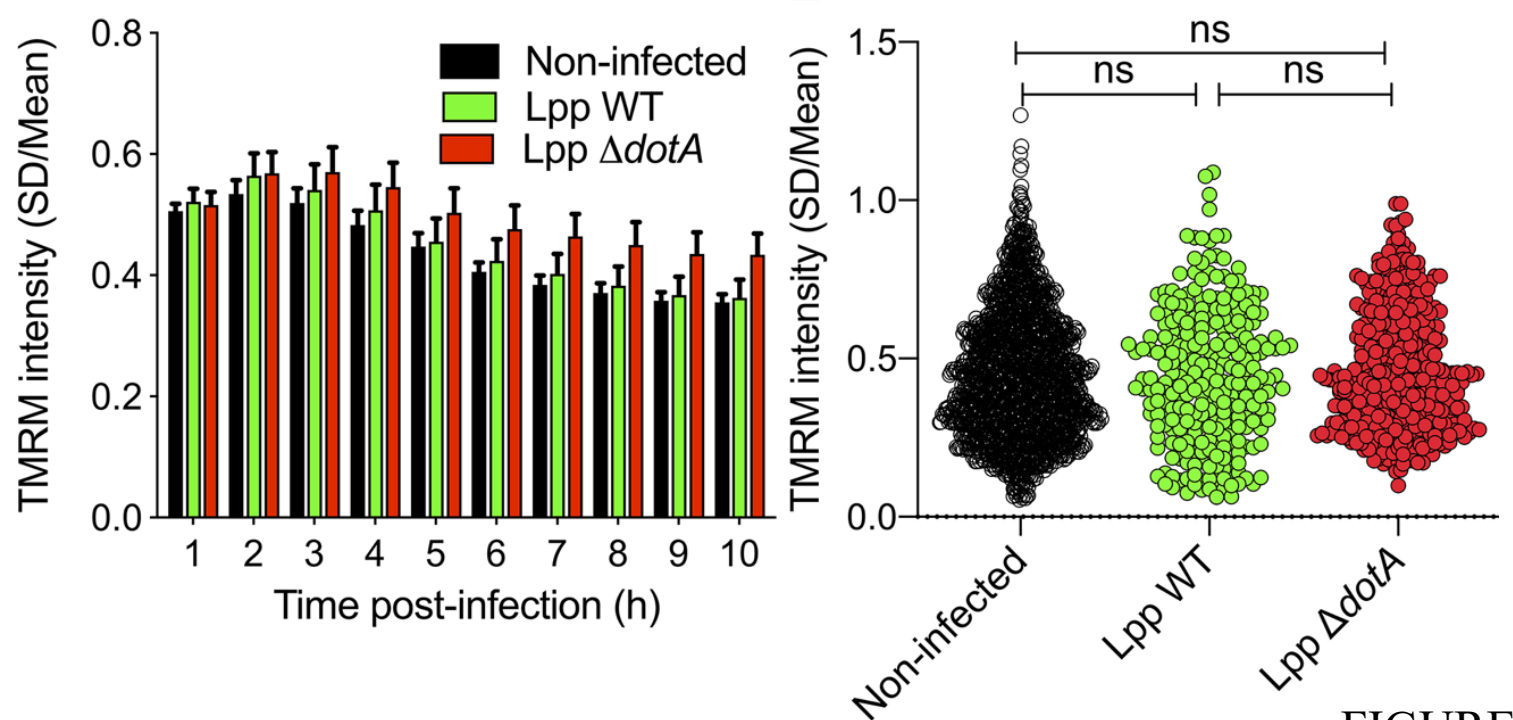

FIGURE 1 
bioRxiv preprint doi: https://doi. org/10.1101/2021.05.12 443790; this version posted May 14,2021 . The copyright holder for this preprint (which was not certified by peer review) is the author/funder, who has granted bioRxiv a license to display the preprint in perpetuity. It is made available under aCC-BY-NC-ND 4.0 International license.
A Forward mode
Reverse mode
B Forward mode
Reverse mode
(synthase)
(hydrolase)
(synthase)
(hydrolase)
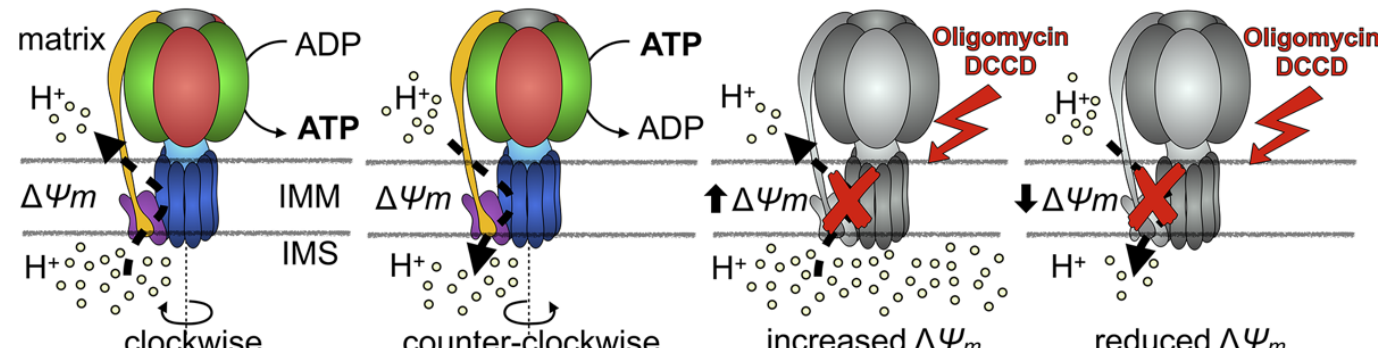

C

+5 min

increased $\Delta \Psi_{m}$

reduced $\Delta \psi_{m}$
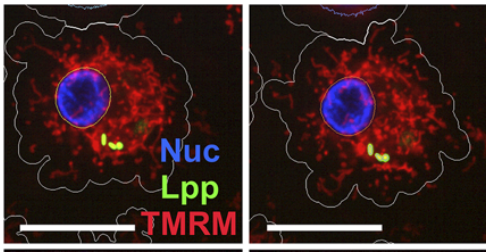

+25 min

$+50 \mathrm{~min}$

Lpp WT + medium

Lpp WT + FCCP
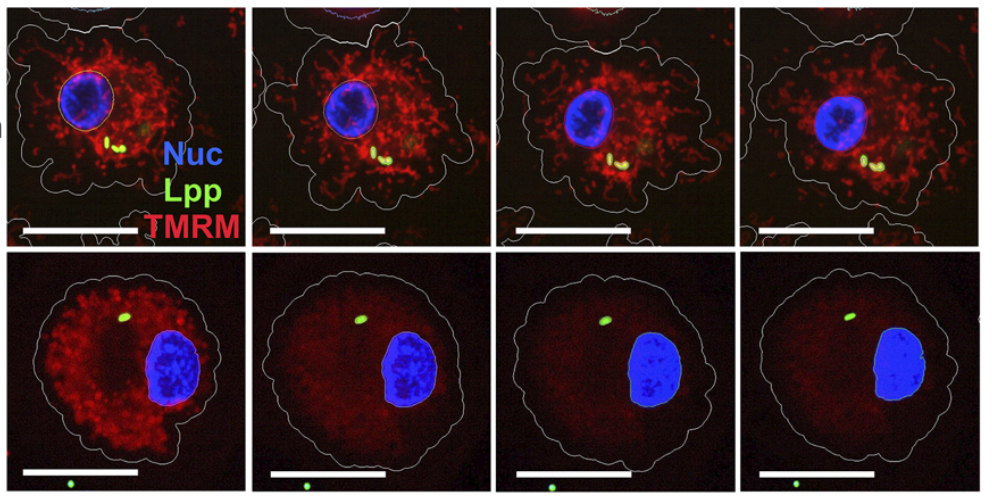

D

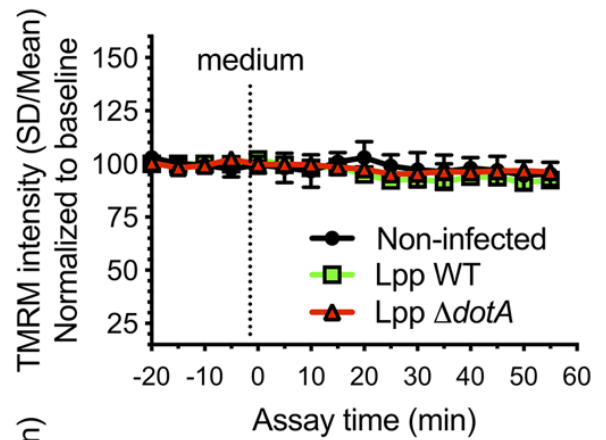

$\mathbf{F}$

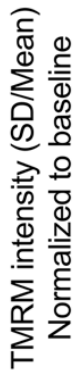

Oligomycin

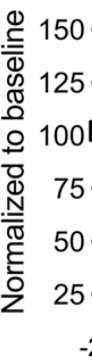

100

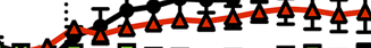

त्र

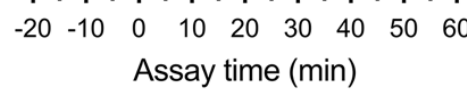

H

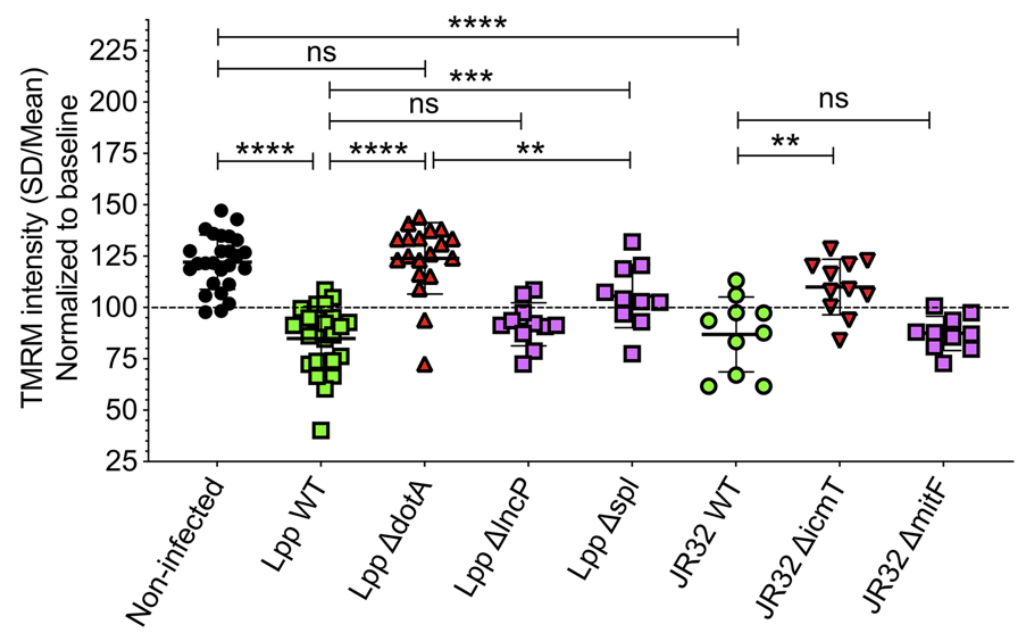

E

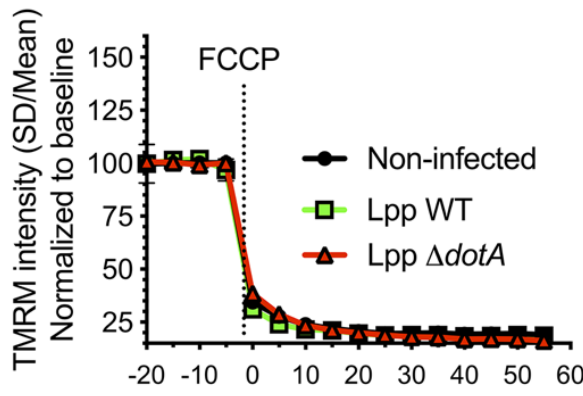

G

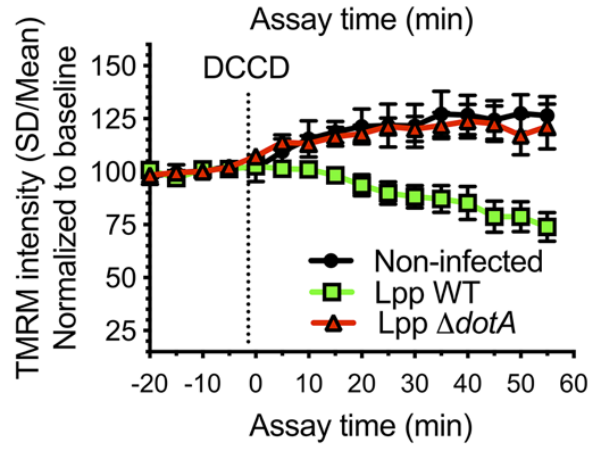


bioRxiv preprint doi: https://doi org/10.1101/2021.05.12 443790; this version posted May 14, 2021. The copyright holder for this preprint made available under aCC-BY-NC-ND 4.0 International license.

A

$-5 \min$

$+5 \min$

$+25 \min$

$+50 \mathrm{~min}$

Non-infected

+ BTB
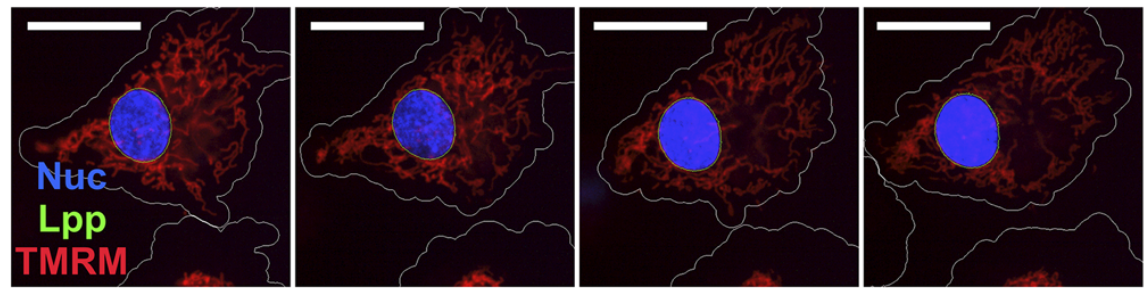

Lpp WT

+ BTB
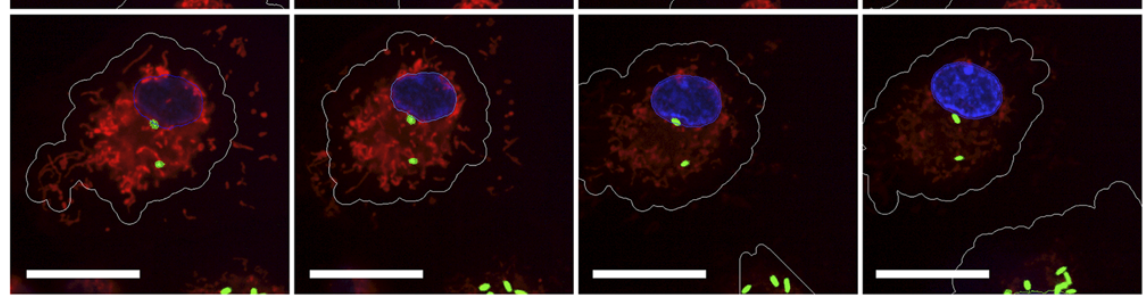

B $\underset{\overline{\mathrm{\sigma}}}{ }$

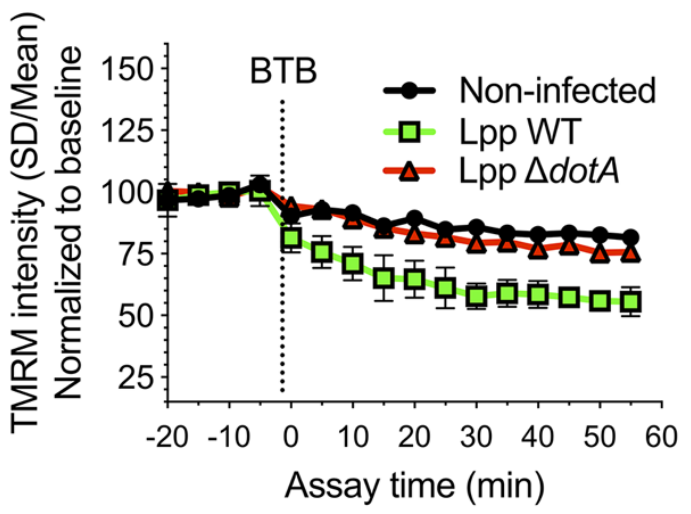

C

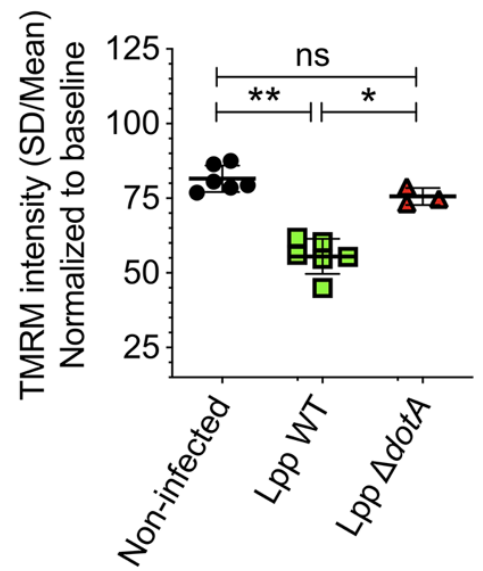

D

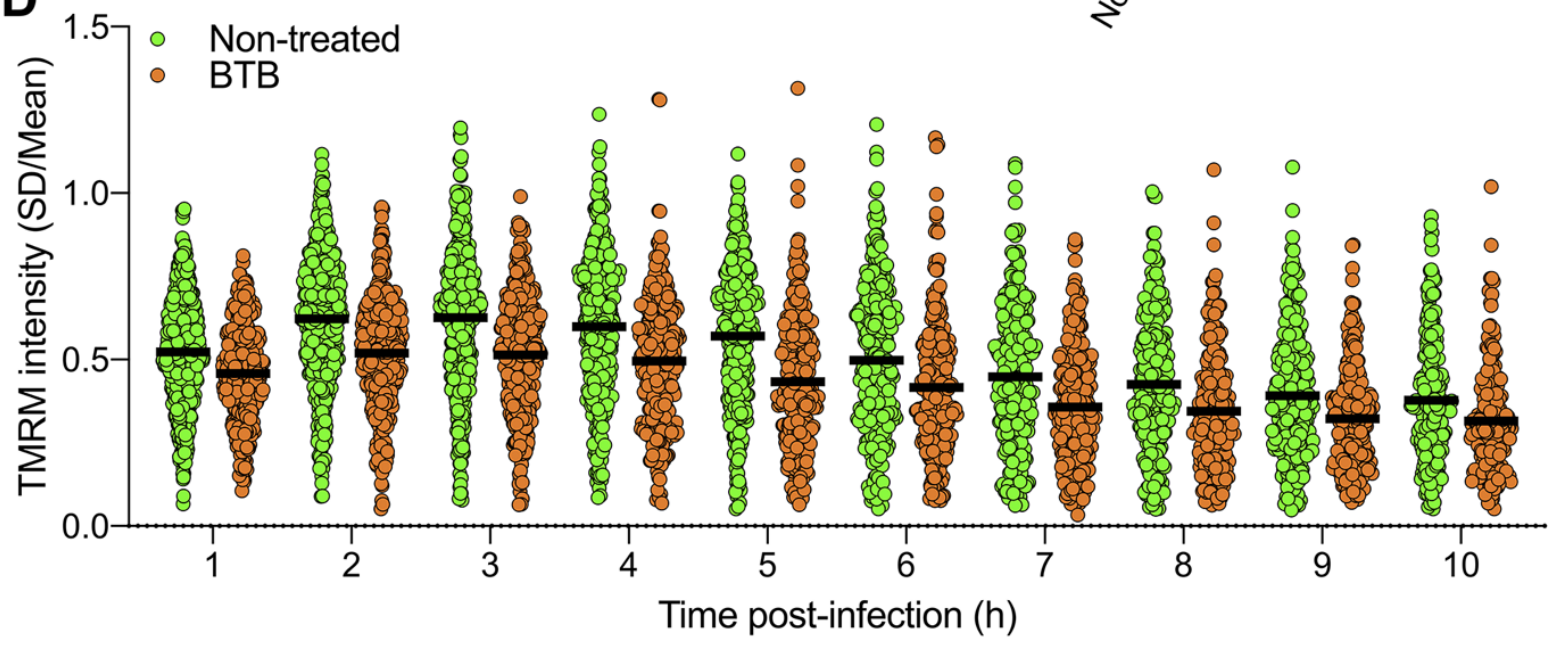

FIGURE 3 
bioRxiv preprint doi: https://doi.org/10.1101/2021.05.12.443790; this version posted May 14, 2021. The copyright holder for this preprint

A

A ns $\quad \square$ Non-treated

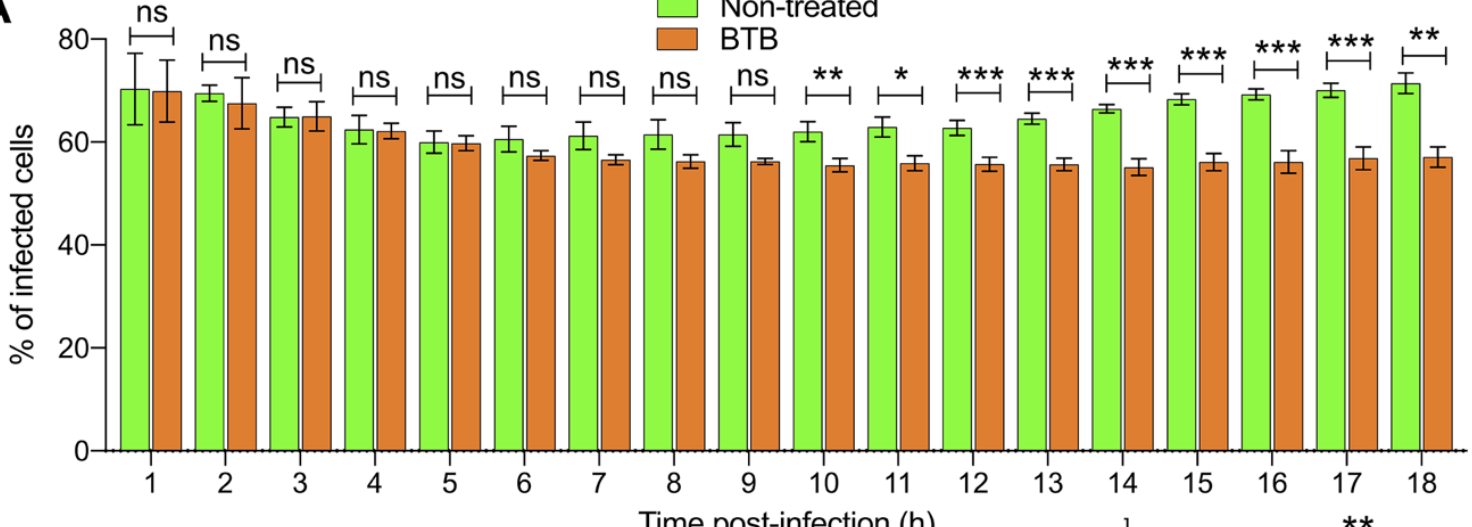

B

6 h.p.i

18 h.p.i
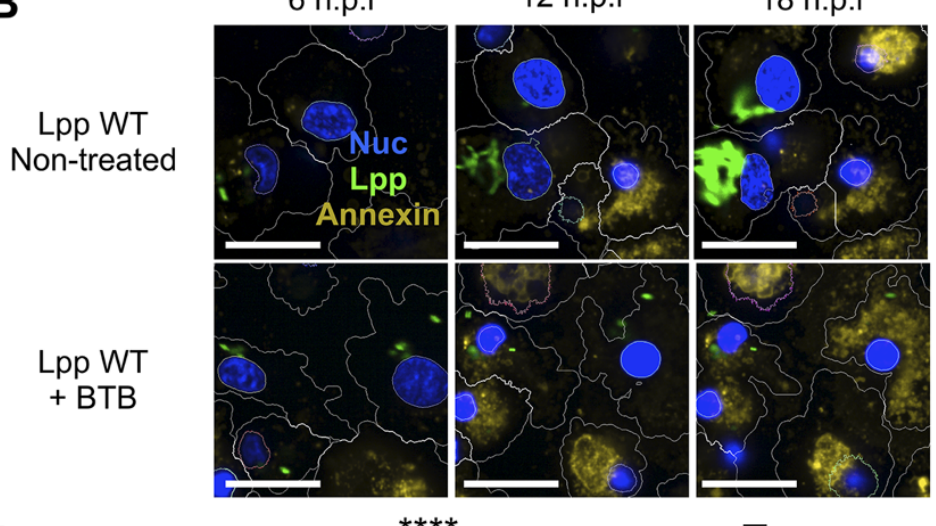

C.
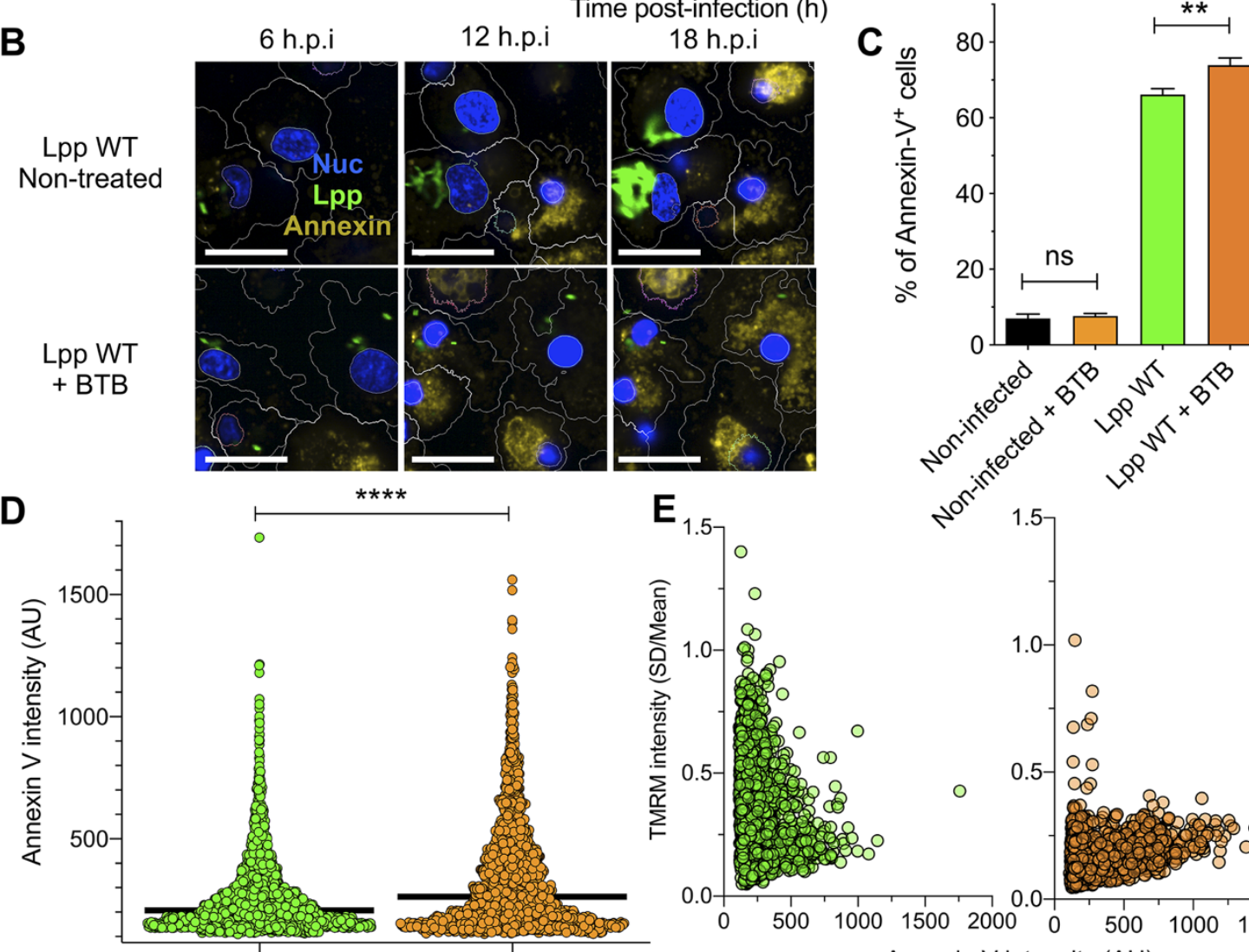

$\mathbf{E}_{1.5}$

$\mathbf{F}$
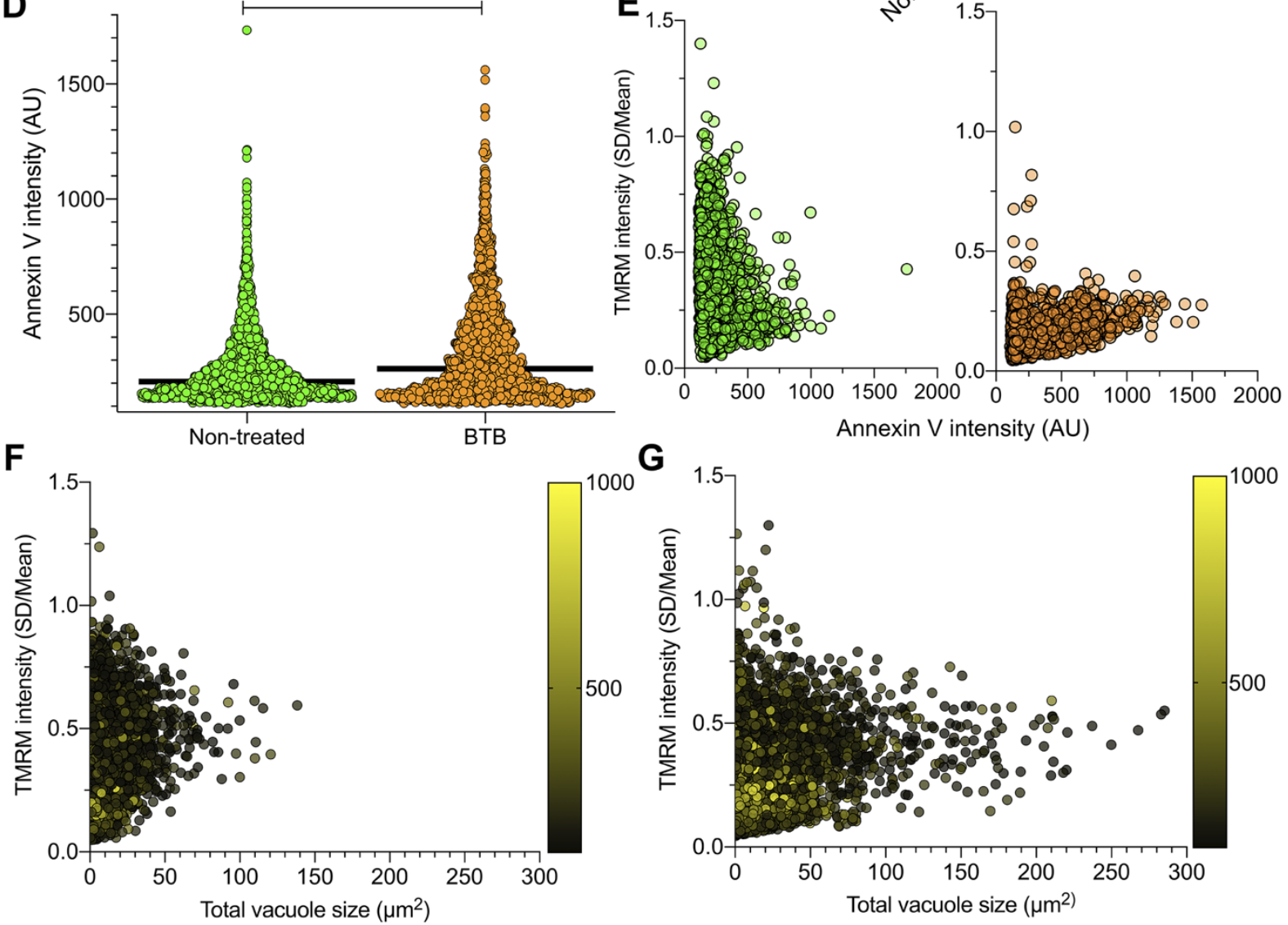

FIGURE 4 